\title{
Models of Metacognition
}

\section{OPEN ACCESS}

Volume: 7

Issue: 2

Month: March

Year: 2019

ISSN: $2320-2653$

Received: 17.01.2019

Accepted: 23.02.2019

Published: 17.03.2019

\section{Citation:}

Thenmozhi, C. "Models of Metacognition." Shanlax International Journal of Education, vol. 7, no. 2, 2019, pp. 1-4.

DOI:

https://doi.org/10.34293/ education.v7i2.303

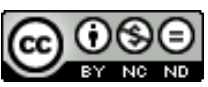

This work is licensed under a Creative Commons AttributionNonCommercialNoDerivatives 4.0 International License

\author{
C.Thenmozhi \\ Principal \\ Adhiparasakthi College of Education, Kalavai, Vellore, Tamil Nadu, India
}

\begin{abstract}
Thinking is a common process. Cognitive ability includes knowledge, memory and metacognition. Knowledge requires memory. These two are inextricably linked. Parents and teachers need to encourage children to take an active role in their learning and show them how to use what they know to the best advantage. Cognition is primarily a mental process. $A$ successful theory of cognition would answer both the epistemological and biological questions. The purpose is to put forward a theory of cognition, that should provide an epistemological insight into the phenomenon of cognition. The concept of metacognition involves knowledge and control of self and control of the process. A metacognitive process consists of planning, strategies, knowledge, monitoring, evaluating and terminating. The Automation of Cognitive and Metacognitive Processes, Social and Emotional aspects of Metacognition, Domain General Versus domain specific Metacognitive Skills. Metacognition, Intelligence and adaptive behaviour, Ann Brown distinguished between knowledge about cognition and regulation of cognition, Private Speech and Development of metacognition is the models of metacognition.
\end{abstract}

Keywords: Cognition, metacognition, strategies, concept and models of metacognition

\section{Introduction}

A sense of success merely reinforce errors. Helping children to cultivate their introspective self-monitoring abilities provide some defence against blissful ignorance. Metacognitive skills of planning, predicting, checking and controlling are the skills typically in children or students who are retarded in academic performance. A problem-solving approach in teaching argues that thinking is essentially unfinished. It is an ongoing activity not about knowledge which once known becomes dead. Knowledge is an instrument of action modifiable and open-ended. By offering challenge We help children to move from dependence to independence, we help them to decode the world, in which they live and to create their authentic responses to it. The basis of metacognition is the notion of thinking about one's thoughts.

\section{Cognition}

Cognition is primarily a mental process. It is an art by which the knower becomes the object known. It is impossible to know an object unless we have cognitively the abstract form of the object we know. Cognition refers to the mental process that transforms the sensory input in various ways codes it, store it in the memory and retrieves it for later use. Perception, imagery, problem-solving, remembering and thinking are all terms that describe the hypothetical stage of cognition. 


\section{Metacognition}

The basis of metacognition is the notion of thinking about one's thoughts. The thoughts can be looked into three different dimensions, viz., knowledge, skill and experience. Metacognition is an awareness of oneself as "an actor in his environment, that is, a heightened sense of the ego as an active, deliberate storer, and retriever of information".

\section{Concept of Metacognition}

The concept of metacognition is used in the sense of steering one's cognitive process. Although 'knowledge' and 'steering' are closely related. There is a slight difference between them. Paris and Winogard (1988) state that metacognition involves:

- knowledge and control of self

- knowledge and control of the process.

\section{Models of Metacognition}

Researches have referred to metacognition as "cognitive strategies", (Paris and Winogard, 1990), "knowledge about executive control systems" (Brown, Harper, and Hedberg, 1994), "monitoring of cognitive processes" (Flavell, 1976), "resources and self-regulating learning" (Osman and Hannafin, 1992) and "evaluating cognitive states such as self appraisal and self management" (Brown, 1996). These are broad terms that are equally important depending on the characteristics of the learner and their approach to their learning. The learners who are aware of their metacognitive processes, they will be doing the following:

1. Planning - deciding what their goals are and what;

2. Strategies - to use to get there; decide what further;

3. Knowledge or resources they need;

4. Monitoring - progress along the way; am I going in the right direction;

5. Evaluating - when I have arrived and

6. Terminating - When the goals have been met (Biggs and Moore).

The concept of metacognition entered the field of cognitive psychology with Flavell.

\section{Models of Metacognition}

Some models of metacognition designed by cognitive psychologists are the following:

\section{The Automation of Cognitive and Metacognitive}

Processes: Kevin Crowley and his associates have demonstrated the relationship between automation of cognitive processes and the emergence of the metacognitive thinking. They suggest that strategies become "Associative Mechanisms", which operate without conscious effort and allow children to devote more mental processing space to the metacognitive and creative aspects of learning.

Strategies: Strategies eventually generalize by forming "goal sketches", which are the result of metacognitive mechanisms decaying from conscious access over time. Goal sketches are generalized strategies not particular to any task, but useful across many, and used automatically based on recognition general task characteristics. Such a general strategy may include working backwards. This strategy is often acquired as children learn that working backwards, through a maze is easily quicker than starting at the beginning. Such a strategy might generalize into another, such as retracing one's steps to a lost item. Later, as children become expert readers, it may manifest as a strategy of looking at the end of a chapter to gather its gist or looking at the review questions before reading. Another such strategy could be attending to errors; if the initial letter to sound mapping in early readers does not become fully automated, it is possible this may result in reduced metacognitive activity, in reading tasks where phonological ability is tested. Thus, meta comprehension, meta memory and meta linguistic abilities may be hindered because extra processing space is required to process phonological input.

\section{Social and Emotional aspects of Metacognition}

John Borkowski and his associates have distinguished between types of strategy knowledge. This knowledge includes what a particular strategy would achieve, what tasks match its use, the range of its usefulness, the benefits of regularly using it, how much effort would be required to use it, and how enjoyable or laborious it would be. Borkowski brings together the components of other models of metacognition (e.g. Flavell and Brown) and provide us with a comprehensive model which encompasses 
cognitive, metacognitive and affective factors, within a developmental framework.

Successful strategy: As children are faced with impasses, they experience success and failure, and they receive feedback which, occurring frequently, develop into ingrained attributions of success and failure. These attributions govern self-esteem, selfefficacy, and the effect, they have on successful strategy learning and their transfer to other content areas.

3. Domain General Versus domain specific Metacognitive Skills: Frank Veenman and his group (200 looked at task and domain - specificity of metacognitive skills in novices. They adopted what they called a "working method" approach. Individuals working methods (metacognitive skills) can vary in quality. Expertise is the height of quality with optimized knowledge and automaticity, and a developed repertoire of self-regularity skills in the domain of expertise. Such quality is the result of repeated practice accumulation of related knowledge, and general level of intelligence. Veenman used to think aloud protocols in problem-solving simulations and coded them for orientation activities, systematic orderliness, accuracy, evaluation, and elaborative activities; together defining a working method. In opposition to the suggestion by Daniela Lucangeli and her group(9) that metacognitive skills are affected by domain-specific attitudes results from Veenman's (20) work reveal consistent differences in the quality working method in favour of higher functioning individuals, and suggests that metacognitive functioning is a general skill that spans across content domains.

4. Mata cognition, Intelligence and adaptive behaviour: Robert Sternberg's (19) Triarchic theory of Human Intelligence that allow individuals to manage their cognitive resources. Sternberg's model consists of performance(encoding, decoding, mapping, application and justification) and knowledge acquisition components(selective encoding, selective combination and selective comparison). These components represent automated cognitive and selective processes used in learning respectively. Sternberg considers meta components to be a key feature of intelligence. The emphasis placed on meta-components is in their association with adaptive behaviour. These adaptive behaviours are considered to be functional strategies or those that act on performance and knowledge acquisition components. Adaptive behaviour goes beyond the knowledge and the cognitive abilities measured by current intelligent tests, and measured by current intelligent tests, and represents the ability, to use these aptitudes to adapt to or shape one's environment.

5. Flavell in his "new area of cognitivedevelopmental inquiry" includes knowledge and regulation of cognition as metacognition.

Knowledge about cognition consisted of:

a. Person variables, or knowledge about oneself and others' thinking;

b. Task variables, or knowledge that different types of tasks exert different types of cognitive demands, and

c. Strategy variables, or knowledge about cognitive and metacognitive strategies for enhancing learning and performance.

\section{Ann Brown distinguished between knowledge} about cognition and regulation of cognition. Knowledge about cognition can be "stable, stable but fallible, of late developing", remaining relatively consistent within individuals. Regulation, on the other hand, can be " relatively unstable, and ageindependent", changing rapidly from situation to situation. Brown's distinction suggests that self regulation is more context than age dependent; one may show self- regulatory behaviour where an adult does not. Regulation may also be affected by patterns of arousal (anxiety, fear interest) and self- concept (self-esteem, self-efficacy).

7. Private Speech and Development of Metacognition: Brenda Manning and her Associates (10) categorized private speech into four levels.

Level 1, the lowest level was associated with task-irrelevant private speech such as effective expression, (emotion or feelings), or off task commenting or questioning.

Level 2, was associated with task-relevant private speech, that did not facilitate task completion, such as giving up or complaining about the task.

Level 3, was associated with task-relevant private speech of facilitative nature that described content, process, or structure, and was used as a strategy to focus attention l(i.e. cognitive focus). 
Level 4, was associated with "higher level" facilitative private speech, such as correcting, copying or reinforcing (i.e. metacognitive focus).

Manning and her associates studied groups of kindergarten children investigating relationships between private speech and autonomy, academic achievement and creativity. Autonomous children, or those who were able to work with little guidance, or assistance, scored low on levels 1 to 3 and higher on level 4 than non -autonomous children. Academically advanced children used fewer level 1 and $2 \mathrm{c}$, and more level 3 and four private speech that less academically advanced children. Creative children used fewer level 1 and more level 4 private speech than less creative children. In each case, autonomous, academically advanced, and creative children used less non-facilitative private speech and more metacognitive private speech, notably the autonomous children, used less low level facilitative private speech, (Level3) unpredicted by the research hypotheses. Manning suggested that these children may have already internalized (automated0 level cognitive self-guiding processes.

\section{Conclusion}

Thus the importance of metacognition is realized in all levels of teaching and learning. Moreover, planning has to be shared between teachers, school library media specialists, and students, where thinking strategies are discussed and evaluation are ongoing. Metacognitive skills are needed when habitual responses are not successful guidance in recognizing, and practice in applying metacognitive strategies will help students to solve problems throughout their lines, successfully.

\section{References}

Dandapani S, A Textbook of Advanced Educational Psychology, Daya, New Delhi, 2000.

Mohan S, Cognitive Perspectives, Alagappa University, Karaikudi, 2005.

Ediger, Marlow \& Bhaskara Rao D, Teaching Reading Successfully, Daya, New Delhi, 2000.

Nagpal, Shakuntala, effective Instructional Strategies for Cognitive Development, Daya, New Delhi, 2001.

Robert Westwood, the Language of Organization, sage, New Delhi, 2001.

Sapra, Rekha, Beyond Cognition: Implications for Education, sage, New Delhi, 2001.

Sharma, Vimlesh, Cognitive styles and Language Comprehension of the Blind, Daya, New Delhi, 2001.

Stephen E little, Paul Quintas \& Tim Ray, Managing Knowledge, Sage, New Delhi, 2001

http://en.wikipedia.org/wiki/Digital_library

http://www.bie.org

http://psychology.wichita.edu

http://www.webopedia.com/

\section{Author Details}

Dr.C.Thenmozhi, Principal, Adhiparasakthi College of Education, Kalavai, Vellore, Tamil Nadu, India

E-mail: thenshri@gmail.com 